\title{
Matthew Barney e o culto sem fim do capitalismo
}

\author{
Alexandre Ferreira Dal Farra Martins ${ }^{1}$
}

\section{Resumo}

Este ensaio pretende apontar algumas relações entre a obra do artista contemporâneo Matthew Barney, o conceito de narcisismo como apresentado por André Green e a ideia do Capitalismo como uma forma de religião, colocada por Walter Benjamin em um fragmento de 1921. O ensaio não pretende tirar todas as conclusões das relações apontadas, mas apenas aproximar estes três materiais que parecem provocar-se mutuamente.

Palavras-chave: Arte contemporânea; narcisismo; capitalismo.

\section{Abstract}

This essay tries to point some connections between the work of the contemporary artist Matthew Barney, the concept of narcissism (as presented by André Green) and the idea of the capitalism as a form of religion, as it was formulated by Walter Benjamin in a fragment he wrote in 1921. The essay does not intend to extract all the conclusions of the presented connections, but tries to put together these three materials, and let them provoke each other.

Key-words: Contemporary art; narcissism; capitalism.

\section{Introdução}

Em seu ensaio Matthew Barney², o escritor e artista plástico Nuno Ramos aponta dois aspectos da obra desse artista americano, que parecem merecer um aprofundamento maior. Nuno faz um pequeno excerto sobre a ideia de narcisismo, para ele presente em Matthew Barney, depois de realizar uma reflexão de muito interesse sobre a relação entre interioridade e exterioridade na arte americana. Esse excerto irá leva-lo de volta a Barney, para então caracterizar a sua obra como uma espécie de surrealismo em que, no entanto, "o inconsciente já foi tomado"3. São esses dois aspectos que Nuno encontra na obra de Barney e que gostaríamos de levar um pouco adiante, aproximando de outro material, que parece jogar uma nova luz sobre os dois assuntos em jogo.

\footnotetext{
1 Pesquisador, diretor e Dramaturgo de teatro.

2 RAMOS, N., Matthew Barney, in Ensaio Geral, São Paulo: Editora Globo, 2007. 


\section{Narcisismo de vida, narcisismo de morte}

O livro Narcisismo de vida, narcisismo de morte 4 já se tornou um clássico da psicanálise. Publicado em 1982, por André Green, a obra contém textos de sua autoria que giram em torno do narcisismo. A perplexidade para que o título aponta dá notícia da complexidade do conceito. Sem que se chegue evidentemente a uma definição ou a uma formulação capaz de dar conta do assunto, Green aponta para diversas características do narcisismo - dispositivo presente na vida psíquica de todos nós seja em seu aspecto ligado à estruturação do Eu, seja em seu aspecto ligado ao seu esvaziamento, à sua morte.

Uma das principais características que o livro aborda em relação ao narcisismo é, ao que parece, a sua tendência à unificação. O psicanalista não deixa de apontar, inclusive, uma espécie de perigo "meta-narcísico" que a teoria do narcisismo corria, em sua primeira formulação por Freud:

o narcisismo [em Freud] era um chamariz tão eficaz que fazia a própria teoria sofrer a sedução da qual ele mesmo era a expressão: a ilusão unitária, recaindo desta vez sobre a libido. Freud decidiu, então, por fim a esta peripécia de seu pensamento propondo a última teoria das pulsões $(. . .)^{5}$.

É, pois, em várias instâncias, e de várias maneiras, que o narcisismo tende a criar uma ilusão unitária, a unificar o que foi separado, a tornar (ilusoriamente) uno aquilo que é duplo ou múltiplo. Esse movimento é o que permite ao Eu, em um determinado momento do desenvolvimento do sujeito, perceber-se enquanto Um, mas também é o que, na tentativa de mantê-lo puramente unitário, pode levar a um movimento de morte - a um "suicídio lento" como coloca Green.

Em linhas gerais, o Eu narcisista é resultado de uma ferida. Esta ferida pode ter várias origens, mas é também a reação do Eu narcísico que o define enquanto tal: "certamente, a ferida narcísica infligida à onipotência infantil direta ou projetada sobre os pais é algo que diz respeito a todos nós. Mas é claro que alguns nunca se restabelecem, mesmo depois da análise”. ${ }^{3}$ A defesa do Eu narcísico, primordialmente em um movimento de vida, mas que, levado ao paroxismo torna-se movimento de morte, é a transformação do objeto de desejo (inicialmente, a mãe), em um desejo voltado para si mesmo - um desejo pelo próprio Eu. Ou, nas palavras de Green, em um desejo pelo

4 GREEN, A., Narcisismo de Vida, Narcisismo de Morte. São Paulo: Escuta, 1988.

5 Idem, p. 10 (grifo nosso).

6 Idem, p. 17 
Um, que apaga o desejo pelo Outro. Por definição o desejo é, justamente, o desejo pelo objeto, por aquilo que descentra o sujeito em busca de um objeto externo que o satisfaça. Então, embora seja determinante para que este Eu se constitua, o desejo pelo Eu é também o movimento de fim do desejo, de ausência de movimento no sujeito - que leva à sua morte, embora isso de fato talvez não possa chegar a concretizar-se realmente. Assim, "só poderemos falar de uma 'tendência', à redução ao nível zero, da excitação, isto é, da vida"'. A tendência ao Uno, à unificação dos contrários, à unificação dos gêneros, do sujeito e do objeto, e ao redirecionamento do desejo para o próprio Eu, se inicialmente o torna Um, corre o risco de tornar-se neutralização de todo o movimento descentralizador, portanto, do próprio desejo - e da vida.

Mas o interesse em mobilizar aqui a teoria do narcisismo reside no fato de que todas essas características parecem adequar-se a uma descrição da obra de Matthew Barney - notadamente do seu ciclo de filmes Cremaster. Com efeito, o próprio artista justifica o título da obra ${ }^{8}$ a partir da ideia de um "sexo puro" (unitário, portanto), anterior a todas as determinações de gênero, culturais e antropológicas - a uma espécie de libido pulsante, anterior à própria separação entre masculino e feminino. Daí, inclusive, as diversas figuras andrógenas presentes no ciclo, sobretudo em Cremaster $4 \mathrm{e}$ Cremaster 3 ("os inconvenientes da diferenciação sexual devem ser suprimidos pela autossuficiência") ${ }^{9}$. Mas mesmo as figuras mais marcadamente femininas ou masculinas presentes em Cremaster parecem carregar a marca da androgenia narcísica.

Na primeira parte de Cremaster 3, por exemplo, acompanhamos a trajetória de uma figura bastante masculina em sua aparência e figurino. Interpretada pelo próprio Matthew Barney, se introduz como uma espécie de sabotadora no Chrysler Building, em Manhattan, edifício onde o filme se passa. Após encher um dos elevadores com cimento, trepa pelo fosso do elevador em direção aos últimos andares ${ }^{10}$. A certa altura, esta figura é levada a uma espécie de sala de tortura, que também se assemelha a um consultório ginecológico. Ali as roupas do homem são retiradas e, vemos então,

7 Idem, p. 26.

8 Cremaster é o músculo, no homem, que possibilita a movimentação dos testículos, para cima e para baixo, a partir de estímulos como o frio e o calor. Em uma entrevista, Matthew Barney aponta a sua inspiração para a obra, como tendo residido na ideia de uma "sexualidade pura", anterior à divisão em gêneros. Esta entrevista está no seguinte endereço: http://www.youtube.com/watch?v=VJfl1LRKOtc.

9 Idem, p. 211.

10 Este movimento de ascensão clandestina ao topo fálico do Chrysler Building também sugere uma fuga da castração que só pode, como é o caso, resultar na morte do sujeito. 
que novamente não se trata exatamente de um homem. No meio das suas pernas não há um pênis, mas uma espécie de protuberância externa de formato ambíguo, que se refere claramente ao elemento andrógeno que mencionamos. A própria matéria branca e disforme, espécie de gosma, a parafina presente em todos os Cremaster, parece apontar para essa tendência ao Uno, ao indiferenciado, que é uma das principais características do narcisismo. Ainda sobre esse ponto, cabe apontar para um aspecto do narcisismo que aparece, de forma quase didática, sobretudo no filme Cremaster 3. Trata-se do complexo da mãe morta.

\section{A mãe morta}

Uma das possíveis causas para a ferida narcísica, que leva ao movimento narcísico do Eu, segundo Green, é o complexo da mãe morta. Evidentemente, esse se refere não necessariamente à morte real da mãe. No entanto, a "uma imago que se constitui na psique da criança, em consequência de uma depressão materna, transformando brutalmente o objeto vivo, fonte da vitalidade da criança, em figura distante, átona, quase inanimada, impregnando muito profundamente os investimentos de certos sujeitos que temos em análise e pesando sobre o destino de seu futuro libidinal, objetal e narcisista"11. Green desenvolverá o complexo lindamente em um dos melhores textos do livro, e mostrará as consequências que a mãe morta pode trazer para a vida, sobretudo amorosa, do sujeito. É impressionante como esta descrição inicial que André Green faz do complexo parece poder ser atribuída integralmente a uma das passagens de Cremaster 3.

No início do filme há, após uma passagem situada em uma espécie de ilha, que funciona como uma introdução, uma longa cena que inicia toda a sua primeira parte e que se passa no interior do edifício. Nessa passagem, uma mulher branca, magra, nua, cujo corpo parece em parte já desfigurado pela morte, embora ela ainda respire e esteja (um pouco) viva, é retirada por alguns gângsteres e por um menino do subsolo do edifício e levada à superfície (o que sugere que o local onde estava esta mãe morta é uma espécie de núcleo da própria arquitetura do filme, local da fundação, por assim dizer, da obra). Carregada pelos gângsteres, seguidos da criança (que se configura como o filho), trazida a uma espécie de hall, no piso térreo, e colocada dentro de um carro preto, antigo. Ali está uma águia, que rodeia o corpo quase morto da mulher. $\mathrm{O}$

11 Idem, p. 239. 
menino também entra no carro, ao lado da mãe "morta". Em seguida ocorrerá uma das mais belas cenas do filme. Nela cinco carros passam a rodear o carro preto, onde está a mulher, a águia e a criança. Passam a trombar nele, como se fosse uma espécie de linchamento, até reduzi-lo a um pequeno pedaço de metal.

Entrando na cena mencionada acima, esse pedaço de metal será colocado na boca da figura principal (interpretada por Barney). Sugere-se novamente que esta mulher continua ocupando um lugar central na arquitetura psíquica da personagem, e do filme como um todo, mesmo depois de morta pela segunda vez. Isso se deve, pois ela foi retirada da terra, onde já estava como que "morta", colocada dentro do carro e reduzida a um pedaço de metal. Com efeito, como coloca Green, ainda sobre este complexo:

"o paciente tem a sensação de que pesa sobre ele uma maldição, a da mãe morta que não acaba de morrer e o mantém prisioneiro. A dor, sentimento narcisista, retorna à superfície. (...) os objetos do sujeito ficam sempre no limite do Eu, nem completamente dentro nem totalmente fora. E isto porque o lugar está ocupado, no centro, pela mãe morta"12.

É claro que uma interpretação como essa sempre trará à tona alguns dos aspectos de uma obra em detrimento de outros. Temos consciência de que a obra de Barney não se reduz ao conceito de narcisismo, muito embora a sua interpretação segundo essa lente pareça bastante frutífera. Mas é outro aspecto do conceito de narcisismo que nos levará à outra ideia que se quer analisar neste ensaio. Essa permitirá trazer à tona um texto que parece jogar nova luz sobre a ideia de que, em Barney, "o inconsciente já foi tomado." Mas precisaremos, para isso, apresentar ainda mais um aspecto do narcisismo.

Green aponta para um nível sacrificial de tal movimento, em que ele é realizado, também, para um Outro: "esta forma de suicídio revela que a inanição objetal, a consumação, são sacrificadas para o amor de um Deus terrível (...) A autopunição torna-se a melhor proteção contra a castração"13. Esse apontamento que ocorre quando descreve a tendência já citada do narcisista a uma espécie de suicídio lento que, aos poucos, em decorrência de uma defesa frente ao risco que o desejo pelo objeto representa, vai fazendo com que o sujeito tenda ao nível zero de excitação.

O movimento mencionado pelo autor refere-se a uma negação da castração que decorre de uma ausência do princípio de paternidade, em que este é tornado negativo

12 Idem, p. 252.

13 Idem, p. 211-212. 
e onipotente - de forma que a castração não poderá realizar-se. Por isso esse Deus terrível é assexuado. Seguindo ainda as palavras de Green, o seu falo é "desencarnado, vazio de substância, molde oco e abstrato"14.

Poderíamos trazer à tona aqui outro aspecto da obra de Barney. Nele são recorrentes os objetos fálicos que guardam essa espécie de "oco", mas esta passagem aponta para outra conexão que gostaríamos, agora, de propor. Esta definição do "Deus terrível", ao qual o narcisista faz o seu sacrifício, precisa ser aproximada de outro material para que, nesta junção, levemos um pouco adiante aquilo que Nuno Ramos aponta sobre o inconsciente "tomado" que Barney apresenta.

\section{Capitalismo como religião}

O fragmento Capitalismo como Religião ${ }^{15}$ foi escrito por Walter Benjamin em sua juventude e propõe um ponto de vista bastante interessante. $\mathrm{O}$ autor procura justamente conceituar o capitalismo, não como um sistema que guarda certas afinidades com outra religião (como pensava Weber), mas sim, como um sistema que funciona como uma religião. Para Benjamin o capitalismo atenderia às mesmas aflições e buscas que as religiões atendem.

Evidentemente que essa inversão no ponto de vista da análise poderia levar-nos às mais diversas conclusões ${ }^{16}$, sobretudo se pensarmos na centralidade que a ideologia passa a ter, já que a própria ideia de religião pertence ao campo tradicionalmente pensado como ideológico. No entanto, não nos cabe pensar sobre as possíveis decorrências a que o fragmento pode levar. As razões que nos levou a trazer o texto para este ensaio se referem às afinidades que podemos encontrar entre a descrição que Benjamin faz desta religião que é o capitalismo e o que vínhamos apresentando sobre o narcisismo - e como todos esses conceitos parecem poder se referir a algo presente na obra de Barney. É importante ressaltar que o próprio André Green explica, no prefácio de seu livro, que o narcisismo é um componente de todo o ser humano, em diversos graus, e todos nós passamos, assim, por momentos mais ou menos narcísicos. Dessa forma, é plausível a sugestão que pretendemos apontar neste artigo: o aspecto do capitalismo que Benjamin ressalta nesse frag-

14 Idem, p. 213.

15 Não há tradução para o português deste fragmento, assim, todas as citações do mesmo se referirão a uma tradução realizada por mim do texto.

16 O filósofo Giorgio Agamben aponta, em diversos textos seus, alguns desdobramentos a que o fragmento poderia levar. 
mento possa se referir justamente àquilo que, nesse sistema, alimenta-se e se reproduz a partir do narcisismo humano. Sigamos à ideia de Benjamin.

Uma das características que o filósofo atribui ao capitalismo, pensado como religião, é o fato de que o seu culto não redime, mas culpabiliza. O culto aqui referido não é evidentemente o culto religioso como conhecemos, mas o próprio dia-a-dia do capitalismo, quer dizer, aquilo que poderíamos chamar de "ritual" cotidiano do sistema: as relações de trabalho, de compra e venda, de troca de mercadorias: regidas pelo fetichismo do produto.

Benjamin aponta que o culto capitalista não tem pausa, é constante: não há, neste sentido, "dia de trabalho", todos os dias são dias de culto, o que aponta novamente para o fato de que o filósofo se refere ao próprio cotidiano. Mas esse culto sem pausa e sem redenção, que se refere a um Deus que não redime, parece em muito se assemelhar ao tipo de dinâmica que persegue o narcisista: "a idealização do Eu é sempre corolária de um sentimento extremamente ameaçador tanto para o objeto quanto para o eu"17. Assim como o narcisismo pode ser visto, em um de seus aspectos, como um sacrifício do próprio desejo do sujeito em função de um Deus terrível, o capitalismo é conceituado por Benjamin como "uma consciência de culpa monstruosa, que não sabe como se redimir, e recorre ao culto, não para nele expiar essa culpa, mas sim para torná-la universal"18.

Mas a principal razão para termos buscado este texto é o fato de que ele aponta para um aspecto que a obra de Barney parece deflagrar, qual seja, a ideia, acertadamente apontada por Nuno Ramos, de que o inconsciente já foi tomado. Ideia essa que, no entanto, Benjamin permite levar muito adiante. A ideia de que os símbolos e as imagens de grandes marcas provenientes da indústria cultural ganhem o caráter de imagens do inconsciente aponta para o fato de que essas imagens façam parte de um jogo que não tem sentido evidente - por isso a referência de Nuno ao surrealismo em Barney. Mas aqui, algo nos chama a atenção, que distancia este "jogo" dos experimentos do surrealismo. É que em Barney este jogo também parece ter, quase sempre, o caráter de um ritual ou de um culto que segue certos códigos.

17 Idem, p. 213.

18 BENJAMIN, W. Capitalismo como Religião. Trad.: Alexandre Ferreira Dal Farra Martins. Disponível em: (http://raumgegenzement.blogsport.de/2009/11/02/walter-benjamin-kapitalismus-als-religion-fragment-1921/). Acesso em: 03 set. 2002. 
No próprio Cremaster 3, já vagamente analisado acima, todo o trajeto do filme se assemelha a uma espécie de culto, ou um código a ser seguido em um ritual. Outro aspecto de todo o Cremaster que aponta para o seu caráter de código ritualístico, mais do que de sonho, é o fato de que diversos símbolos reaparecem nas mais diversas situações. Por exemplo, o símbolo, que é formado por um retângulo com duas abas arredondadas que sobressaem das laterais simetricamente, aparece em todos os filmes da série, e mesmo em outros filmes do artista, como Drawing Restraint 9. Tais símbolos funcionam efetivamente como marcas ou códigos distintivos, unidades que podem surgir no formato de um campo de futebol, em um tonel gigantesco de parafina, ou em uma pequena fôrma de cortar batatas.

Mas essa não é a única característica que aponta para o caráter de ritual ou de culto que aparece nos filmes de Barney. São muitas as passagens desses filmes, em que assistimos a procedimentos, ações realizadas metódica e concentradamente pelas figuras, cuja natureza ou sentido não conhecemos. E que parecem, ademais, não se referirem a nada senão a si mesmas. Essas atividades metódicas, em que aqueles que as realizam parecem conhecer os passos a serem realizados. São, portanto, ações supostamente repetidas, Elas parecem se referir a uma espécie de ritual, de um culto, mas nesse nada aponta para um significado externo às ações, para uma divindade ou o que quer que seja, para quem o culto se realizaria. Este caráter material e imanente (que não se conecta a nenhum tipo de divindade transcendente, externa ao próprio culto em si) do culto também se aproxima da caracterização que Benjamin apresenta do capitalismo. Pois que, segundo ele, nessa religião, Deus perdeu a transcendência - trata-se, pois, de um culto imanente, sem transcendência, sem conexão com algum tipo de dimensão para além de o culto em si.

Esta materialidade pura do ritual, ou do culto é um dos principais motores dos filmes de Barney ${ }^{19}$. Tudo se passa como se os códigos, ritos e procedimentos a que assistimos precisassem acontecer, não por nenhum tipo de necessidade transcendente, mas por uma espécie de necessidade inexplicável e sobretudo material. Inexplicavelmente, por exemplo, é o próprio edifício, em Cremaster 3, que parece clamar para que se realize a dança que finaliza a sua primeira parte (e que resulta na morte da figura principal). Essa espécie de festejo ritualístico, que remete vagamente a uma mistura de danças tradi-

19 Aqui a minha interpretação difere um pouco da de Nuno Ramos, que aponta para algum "nível oculto" de significação que a montagem paralela insinuaria. Tenho a impressão de que não há uma insinuação de um nível oculto de significação, mas somente a uma relação entre os planos que se referem uns aos outros, sem que se refiram, todos, a nada. 
cionais com rituais de iniciação maçons, parece ser como que demandado pela própria materialidade do edifício e de toda a movimentação interna a ele. O culto nunca se refere a nenhum tipo de força externa, transcendental.

Este tipo de religiosidade transcendente é o tempo todo evitada por Barney, que faz questão de fazer com que todos os rituais não tenham um receptor, não sejam destinados a ninguém, mas a si mesmos ${ }^{20}$. Esta continuidade sem fim do culto que não se refere a ninguém externo a ele, mas só à sua própria perpetuação. Ela também parece falar muito daquela intuição de Benjamin sobre a lógica religiosa do sistema capitalista.

Tal intensidade do venerar perpétuo e sem objeto, além de ser narcísica por faltar o objeto de desejo, o Deus a ser adorado e que também é o que é capaz de absolver, parece apontar para muito da intensidade unitária e algo monótona dos filmes de Barney. Neste sentido é interessante perceber como é comum, ao assistirmos aos Cremaster, sentirmos certo tédio, que decorre justamente do fato de que muitas vezes, a certa altura, nós já saibamos o que vai acontecer em certa passagem do filme, mas esta passagem, no entanto, dura ainda muito tempo, muito além do necessário, e durante todo esse tempo, nós precisamos assistir à realização daquilo que nós já sabíamos há muito tempo que iria acontecer. É assim em praticamente todo o Cremaster 1 (a partir do momento em que o jogo entre as uvas e as dançarinas é deflagrado), na cena já citada do linchamento dos carros no Cremaster 3 , durante toda a corrida de motos em Cremaster 4, e em muitas outras passagens.

Cremos que isso não decorre de um erro de roteiro nem de nenhum tipo de falta de qualidade da obra, antes, provém da própria natureza do culto (vazio ou imanente) ali apresentado. Como em uma missa, um casamento, ou em qualquer outra cerimônia que tenha o caráter ritualístico, sempre sabemos o que irá acontecer e, no entanto, precisamos assistir ao acontecimento em si: o culto precisa se realizar, o ritual precisa se dar. E é bem esta sensação que Cremaster nos traz: mesmo não tendo um motivo, mesmo não havendo um objetivo, o culto precisa se realizar, o ritual precisa ser feito. Ou ainda refeito, o que também sugere certa permanência monstruosa daquilo que ali vemos. Este culto vazio e narcísico parece, assim, se referir à própria estrutura da religião que Benjamin aponta no capitalismo: não se trata tanto de estruturas do inconsciente que foram tomadas por imagens da indústria cultural, mas da própria lógica de 
funcionamento do capitalismo transformada nessa espécie de culto vazio, sem um Deus referente, constante e imanente.

Ao final do fragmento, Benjamin escreve um trecho solto, sem conexão direta com o resto: "Comparação entre as imagens sacras de diversas religiões, por um lado, e as cédulas de diversos estados por outro. $O$ espírito que fala por meio da ornamentação da cédula" ${ }^{21}$. É, pois, justamente este espirito que fala por meio da ornamentação da cédula, que parece falar também por meio dos símbolos e dos códigos ritualísticos ou cultuais, vazios, apresentados por Matthew Barney em Cremaster. Se pensarmos em Benjamin, este código, este ritual, é justamente o culto sem fim do capitalismo.

21 BENJAMIN, W. Capitalismo como Religião. Trad.: Alexandre Ferreira Dal Farra Martins. Disponível em: (http://raumgegenzement.blogsport.de/2009/11/02/walter-benjamin-kapitalismus-als-religion-fragment-1921/). Acesso em: 03 set. 2002 